\title{
A firm foundation
}

\author{
Dawn S. Hui, MD, and Richard Lee, MD, MBA
}

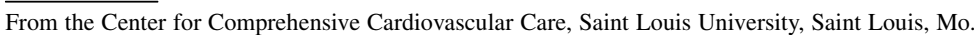 \\ Disclosures: Authors have nothing to disclose with regard to commercial support. \\ Received for publication Feb 9, 2017; accepted for publication Feb 15, 2017; available ahead of print March 25 , \\ 2017. \\ Address for reprints: Richard Lee, MD, MBA, Center for Comprehensive Cardiovascular Care, Saint Louis Uni- \\ versity, 3635 Vista Ave, Saint Louis, MO DT 13F (E-mail: rlee@slu.edu). \\ J Thorac Cardiovasc Surg 2017;153:1437 \\ $0022-5223 / \$ 36.00$ \\ Copyright (C) 2017 by The American Association for Thoracic Surgery \\ http://dx.doi.org/10.1016/j.jtcvs.2017.02.038
}

In June 2016, Dr Coselli's eloquent presidential address at the 96th Annual Meeting of The American Association for Thoracic Surgery provided a unique insight into the role of competition in cardiovascular surgery. ${ }^{1}$ In it, he drew forth the phrase "perspiration to inspiration." In this issue of the Journal, Drs Kraev and Merritt-Genore ${ }^{2}$ provide a thoughtful reflection on cardiothoracic training from the perspective of recent graduates. Their essay, part of the Young Surgeon's series, gives sound advice on the nuts and bolts of how to make perspiration fruitful. On the face of it, this may appear relevant only to those in training, but it also will hold interest for those on the closer end of the spectrum to "inspiration."

Two hallmarks of cardiothoracic surgery are persistence and innovation. As mentioned in Dr Coselli's speech, John H. Gibbon's heart-lung machine is the most famous of these. Compared with his 23-year struggle to create this foundation of modern heart surgery, and considering the end of Dr Gibbon's clinical practice after only 4 cases, the pace of innovation in today's age seems hyperaccelerated. In the lifetime of our current trainees, significant paradigm shifts including self-driving cars and percutaneous therapies for a range of mitral valve pathologies are in the realm of possibility. As technology has facilitated data acquisition, analysis, and dissemination of scientific results, the collection of facts and evidence to memorize and understand grows at an exponential rate; further, the skills necessary to critically judge and contextualize this information become more complex. Learning modalities have moved from pen and paper to electronic, while incorporating simulation and even virtual reality. As well, a broadening range of specialized skills is expected of new graduates. This is all to say nothing of the old challenges of dealing with hospital and group politics, highly complex patients, and practice management, among others.

This Young Surgeons' Note is a reminder, in this tempest of change, that the traditional values are what will anchor

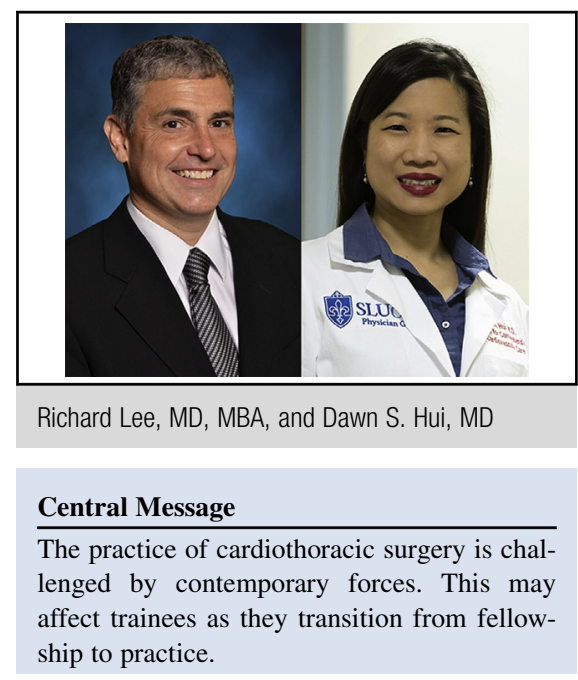

See Article page 1434.

the next generations of trainees. Unlike other aspects of contemporary life, there are no shortcuts in cardiothoracic surgery and no substitutes for precise attention to minute details or learning the bypass machine from the ground up. As our field faces greater scrutiny of quality, more complex patients, and a broader range of therapeutic options, the solution lies not in present practices but in past values. However, this creates a competitive situation for the practice of cardiothoracic surgery. We should be encouraged that the application process is likely to select trainees who are best equipped to manage the friction between these conflicting paradigms of performance. The challenge of those on the "inspiration" end is to guide them in this management, not only during training but also in the critical early years of transition to practice. To this end, our institution is administering a survey of junior and senior cardiothoracic surgeons on attitudes and practices during this transition period. As with patient care, objective data are needed to support and create best practices. We encourage continued reflection and study in this area to continue building on this great foundation.

\section{References}

1. Coselli JS. Competition: perspiration to inspiration "Aut inveniam viam aut faciam" J Thorac Cardiovasc Surg. 2016;152:1215-22.

2. Kraev A, Merritt-Genore H. Hello from the other side: what I wish I'd done differently in training. J Thorac Cardiovasc Surg. 2017;153:1434-6. 